\title{
Correction to: Repeated Cryoablation as Treatment Modality After Failure of Primary Renal Cryoablation: A European Registry for Renal Cryoablation Multinational Analysis by Sundelin MO, Lagerveld B, Ismail M, et al., J Endourol 2019;33(11):909-913. DOI: 10.1089/end.2019.0444
}

\footnotetext{
TN THE November 2019 issue of the Journal of Endourology (vol. 33, no. 11; 909-913) the article titled 1 "Repeated Cryoablation as Treatment Modality After Failure of Primary Renal Cryoablation: A European Registry for Renal Cryoablation Multinational Analysis” by Sundelin et al. requires correction.

The authors discovered that the Funding Information was inadvertently left out. The authors have revised the Funding Information as below:
}

The present study was in part funded by the Health Research Fund of Central Denmark Region.

The online version of the article has been corrected to reflect this. The authors apologize for this error. 